\title{
Cultivation on Students' Professional Ability for Middle Vocational Undergraduate
}

\author{
Bing Yang ${ }^{a}$, Jianfeng $L u^{b}$ \\ College of Finance and Trade, Bohai University, Jinzhou, 121013, China \\ ayangbing2884567@163.com, blujianfeng9999@126.com
}

\begin{abstract}
Keywords: middle vocational undergraduate; vocational ability; cultivating strategies; ability constitution; multiple intelligence theory
\end{abstract}

\begin{abstract}
Middle vocational undergraduate education is a higher level of vocational education, after the rapid development in recent years, has made remarkable achievements, made a contribution to the popularization of higher education. Also exposed a lot of problems in the process of development, based on the theory of multiple intelligences, analysis of vocational undergraduate students occupation ability, put forward the strategy of cultivating vocational college students occupation ability, for service to healthy and stable development of middle undergraduate education. The ability to include: professional and technical ability, innovation ability, team cooperation ability and social adaptation ability; the training strategies include: establishing the scientific concept of vocational education, reforming the curriculum structure of specialties, establishing a multi-faceted teaching staff, innovating the evaluation system of education, through the school-enterprise cooperation to highlight the ability characteristics, market-oriented education activities, improve career planning education, explore diversified school mechanism.
\end{abstract}

\section{Introduction}

In recent years, the rapid development of vocational education in China, the steady progress of vocational education system, to improve the quality of workers, promote economic and social development and promote employment has made important contributions. At the same time, vocational education cannot fully meet the needs of economic and social development, the structure is not reasonable, the quality to be improved, the condition of running a school is weak, institutional mechanisms is not smooth. Accelerate the development of modern vocational education, is the inevitable requirement to further to implement the strategy of national rejuvenation through science and education and the strategy of reinvigorating China through human resource development, is effective way for everyone to become useful only, to share the life opportunities, create greater talent bonus, is of great significance for building a well-off the society and realize the great rejuvenation of the China dream, must be placed in a more prominent strategic position.

Middle vocational undergraduate education is a higher level of vocational education, after the rapid development in recent years, has made remarkable achievements, made a contribution to the popularization of higher education. The new era of vocational education, is to continue to innovate the traditional mode of education, the inherent concept of running a school to break through, to explore innovative education. It is of great significance to explore and establish a vocational education training system in line with China's national conditions, to strengthen vocational skills and innovation ability, to promote quality education, and to improve vocational ability training, and to cultivate applied technical talents and modernize construction. This paper puts forward the strategy of cultivating professional competence of middle vocational students, which is not only the important task of cultivating talents in vocational education in the new period, but also the objective requirement of sustainable development of vocational education.

\section{Basic Concept Definition}

This research involves four basic concepts:

(1) Middle vocational undergraduate, undergraduate is the basic component of higher education, 
generally carried out by the university or college, very few high vocational colleges have been applied undergraduate education. Undergraduate education is more important than the theory of specialized general education, and application-oriented undergraduates focus on the application of professional education and practical skills education, students normally receive a graduation certificate and certificate of bachelor's degree after graduation. Middle vocational undergraduate enrollment is a special form of undergraduate enrollment, and middle vocational technical schools students to participate in college entrance examination, and then entering undergraduate.

(2) Capacity is to complete a goal or task embodied in the quality, is necessary subjective conditions for the successful completion of an activity. People have different ability to show in the activity. Ability is a direct impact on the efficiency of activities, and activities to complete the psychological characteristics of personality.

(3) Occupation is to participate in social division of labor, the use of specialized knowledge and skills for the community to create material wealth and spiritual wealth, access to reasonable return, as a source of material life, and to meet the work of the spiritual needs. Occupation with the progress of human society and labor division generated and developed is the result of the development of social productivity and the progress of science and technology. A country's economic system, industrial structure and scientific and technological level determines the social composition of the occupation, the development of social occupation and objectively reflects the economic, social and technological and other fields of development and structural change.

(4) Professional competence refers to the sum of the ability of practitioners to use their acquired knowledge to fulfill the competency characteristics required with the purpose of occupation activities and the ability to adapt to changes in their career. Professional competence includes three basic elements: the ability to be qualified for a specific occupation, performance qualification; the professional quality after entering the field; the career management ability after starting a career.

\section{Multiple Intelligence Theory}

The traditional theory of intelligence that human cognition is one, individual intelligence is single and can be quantified. The multiple intelligences theory argues that intelligence is the ability of an individual to solve a problem or create an effective product under the value of a social or cultural environment. Everyone has at least the intelligence of the language, the logical mathematical intelligence, musical intelligence, spatial intelligence, physical exercise intelligence, interpersonal intelligence, intrapersonal intelligence and natural intelligence. There is no such thing as pure intelligence and the only way to achieve the goal. Everyone will find their own brain resources in their own way. This does not meet the various individual talents to true intelligence, created the different between people. The ability to exist not in the form of integration but in a relatively independent form, the modern society is the era of the need for all kinds of talent, which requires education must promote the comprehensive development of all intellectual intelligence, personality get the full development and perfect. Multiple intelligences theory emphasizes pluralism, diversity, creativity and development.

According to the theory of multiple intelligences, a person is smart or not, not only in the academic aspects, but also in other aspects of intelligence. Middle vocational undergraduates in language and mathematical logic are weak, but in other aspects of intelligence have their own strengths. And the corresponding level of ordinary university undergraduate students compared to the same level of different types of talent, there is no distinction between high and low intellectual levels only the different types of intelligent structure. Higher vocational education and general higher education training object, but there are differences in the type of intelligence, this difference determines the two types of education, and training objectives are different. Society needs different types of talents, so the same level of two different types of education. Education process as long as the individual's strengths from the intelligence to be guided, everyone has unlimited potential can be tapped.

The theory of multiple intelligences embodies the requirements of the comprehensive development of undergraduates. The theory of multiple intelligences from the perspective of brain 
science and anthropology that normal people, are a combination of a variety of intelligent organism can rely on their own preferences or cultural preferences to mobilize or connect to these intelligence. This shows that everyone has a comprehensive development of physiological basis of multiple intelligences, with the full development of the possibility. The full development of the potential of each student is no longer an administrative instruction executed by school education. It is scientifically grounded and achieves educational goals that can be achieved by students' subjective initiative. From the theory of multiple intelligences, it is entirely possible to realize the all-round development of undergraduates.

\section{Composition on Students' Professional Ability for Middle Vocational Undergraduate}

As a high-quality laborer and application-oriented talented person oriented to the front line of production, service and management, the middle vocational students should have the following professional abilities:

(1) Professional and technical ability. Professional technology is specialized in a particular area of work or occupation required work knowledge, theory, operational skills and skills. Professional and technical ability training is one of the important tasks of vocational education. From the functional point of view, is engaged in the occupation work ability where necessary, is qualified for the job, is the core ability of survival, emphasizing the application of professional and targeted, pay attention to professional knowledge and skills. With the upgrading of technology and professional post updates, professional and technical capabilities have to continue to develop.

(2) To explore innovative ability. All kinds of intelligence factors and ability quality in the new level of integration, interaction, combined with the formation of a joint force. According to the goals and needs of the flexible and creative use of all knowledge and information is known, has the ability that put forward insights, innovative, pioneering and positive social value-based spiritual or material product. The innovation ability of undergraduates in middle vocational school mainly includes the ability of new product development or technological transformation, creating high-quality products to meet the needs of consumers, and improving the competitiveness of enterprises and the ability of sustainable development.

(3) Teamwork ability. Based on the team, play team spirit, and complement each other in order to achieve maximum team work efficiency. Cooperation is a modern basic quality and character, if a person can not cooperate sincerely with people, it can not be successful. Teamwork is to allow everyone to play the most powerful force. The starting point of the team is to respect individual interests and achievements, and the core is to the common goal of cooperation, the highest level is all members of the high centripetal force and high cohesion, unity of individual interests and overall interests, to ensure the efficient operation of the team.

(4) The ability of social adaptation. In order to better survive in the society and the psychological, physiological and behavioral changes in the various behavioral changes, and society to achieve a harmonious state of adaptability. Usually includes social communication ability, human ability and interpersonal skills. Middle vocational undergraduate students from the environment is relatively superior, constraints is relatively relaxed university campus, into the rhythm faster, more stringent management, the environment is relatively poor production line, a huge contrast to each person's life model poses a challenge, how to adjust themselves to adapt to the new environment as soon as possible, it relates to the social adaptability problems.

\section{Cultivating Strategies on Students' Professional Ability for Middle Vocational Undergraduate}

Based on the theory of multiple intelligences, according to the professional competence of middle vocational undergraduate, with reference to the relevant literature, combined with the author's middle vocational teaching experience, this paper puts forward the following strategies:

(1) Establish a scientific concept of vocational education. The educational idea is formed in the process of educational practice. The rational understanding of educational development can reflect the essence of education and the characteristics of the times, and indicate the direction of 
educational development scientifically. Middle vocational undergraduate education is facing the new situation of service demand change, student source change, layout structure adjustment and training goal expansion, etc. and must update the education idea. Changing the traditional concept of underestimating the vocational education and confirming that vocational education is also the position to cultivate diversified and versatile talents; to change the concept of discipline-based, establish comprehensive vocational ability and comprehensive quality education view; jump out the circle of training post ability and professional ability, focusing on the training of key ability and practical ability; change the vocational education for the ultimate education awareness, the establishment of lifelong education.

(2) Reform the professional curriculum structure. Human thinking can be roughly divided into two kinds of abstract thinking and image thinking. Ordinary undergraduate students tend to abstract thinking, and middle vocational undergraduate students tend to image thinking. Talents needed by the society include skills, technology, engineering and academic, middle vocational undergraduate students are skilled personnel. The traditional curriculum is arranged according to the structure of large and logically disciplinary order. It is an effective way to cultivate the academic talents by imparting the objective knowledge which is practical and suitable for students with strong abstract thinking. The course setting of the middle vocational school is to jump out of the framework of the subject system, aim at students' thinking mode, process knowledge and supplemental declarative knowledge. and make students obtain the subjective knowledge of self construction, on this basis, acquire the relevant theoretical knowledge and skill acquisition.

(3) The establishment of composite teachers. Teachers are the leaders of the educational purpose, the designer, the leader and the organizer of the educational activities; Teachers are the motive force of educational activities, and promote the development of educational process and the realization of educational goals. To develop students' multiple intelligences, teachers must have multiple intelligences, and teacher's intelligent experience is the example of students to develop the intelligence. "Double-type" teachers are the most ideal teachers in vocational education, we must accelerate the construction. Due to the differences of teachers' individual intelligence, teachers' construction emphasizes on individual quality, more consideration on overall structure optimization, and makes all kinds of outstanding teachers become the best teachers' team. The construction of composite teachers should be based on the campus, look outside the school, take a combination of full-time and part-time road.

(4) Innovation education evaluation system. Evaluation is a value judgment activity. Educational evaluation is based on a certain educational values or educational objectives, the use of scientific means, through the collection of information and analysis, the educational activities, educational processes and educational outcomes for value judgments, to improve the quality of education and education decision-making process. Vocational education and other education have the same educational characteristics, but more targeted, so it has its own characteristics. The goal of the construction of vocational education evaluation system is to realize the educational idea of "serving for the purpose, taking employment as the direction, taking the combination of production, teaching and research as the way of reform and development", so that the vocational education can realize the school objectives of "serving the local economic and cultural construction and serving the occupation career development ".

(5) Through school-enterprise cooperation to highlight the ability characteristics. School-enterprise cooperation is a cooperative model established by schools and enterprises, pay attention to school learning and enterprise practice, pay attention to the comprehensive utilization of school and enterprise resources. Vocational education for the pursuit of their own development, do a good job in the quality of education, and business cooperation, targeted training of talent, pay attention to the practicality and effectiveness of talent. From the school, can be timely feedback to the needs of society, enhance students' professional practice ability characteristics; from the enterprise, can use school teaching force, promote scientific and technological achievements to modern productive forces. School-enterprise cooperation is not only the need to cultivate competencies, but also an effective way to cultivate professional competence. The mode of 
cooperation can be the combination of school enterprise, labor and education, school-enterprise interaction and other modes.

(6) Market-oriented educational activities. The market-oriented vocational education, the employment market as the direction of the school, the actual operation ability of students as a school goal, with the market standard to test the effect of running schools, with market resources to support their own development. In the process of the service market, access to their own development space and development momentum, and industry, enterprises and companies to form interdependence, mutual promotion, the development trend of common growth. Vocational education must update the concept of running a school, and strive to deepen the integration with the market; to help students obtain vocational qualification certificate or industry skills and technical certificates. The market as the starting point and the end point of vocational education development, adhere to the service economic and social development, to adapt to the economic restructuring of vocational education requirements.

(7) Improve the career planning education. Career planning is to analyze and determine the subjective and objective factors of personal career choice, to determine the individual's goals and strive to achieve the process of this goal, and the aim is to help the individual to accomplish the career development of each stage, and for the next phase of development for advance planning and preparation. Middle vocational undergraduate education, according to the training objectives and characteristics of students, and guide students to establish the correct career ideals and professional concepts, learn according to social needs and their own characteristics to set career planning, to carry out the ideal education to support a variety of vocational tests, make students fully understand self and self-awareness, establish correct goal, establish correct employment concept and the concept of lifelong learning, help students master the job skills, create conditions for employment and entrepreneurship.

(8) To explore diversified school-running mechanism. Government investment in a single mechanism has been difficult to adapt to the needs of social and economic development, social forces to participate in the school to become a social and economic development needs. In addition to single public and private mechanisms, the vocational education should explore a variety of forms of running schools, to achieve the diversification of the main body, to inject new vitality into the vocational education, expand the development space. Social forces participate in running a school, so that vocational education to achieve the purpose of serving the community, mobilize the initiative of teachers, improve the quality of vocational education. Market regulation has become an important driving force of the diversification of vocational education mechanism, recognize the position in the market and its own functions and values, the use of close proximity with the market, the formation of specialty, and cultivate the market needs professionals.

\section{Conclusion}

Middle vocational undergraduate education is higher than ordinary higher education needs to be closely linked with the type of social education, should be based on social needs, vocational ability training as the primary task, and comprehensively improves the overall quality of students. China's middle vocational undergraduate education do not have a long history, the educational theory is not mature and complete. The realistic educational level cannot meet the needs of the socialist modernization construction, and cannot meet the future demand for high-level skilled talents. In this paper, the application of multiple intelligences theory, aiming at the existing problems of vocational undergraduate education put forward the training strategy to solve the core problem of the sustainable development of middle vocational undergraduate education, to promote the development of middle vocational undergraduate education, improve the quality of personnel training, have important significance to perfect occupation ability training theory. 


\section{References}

[1] W. F. Liu, "Higher vocational education under the diversified mechanism of running a school," Education and Vocation, vol. 99, no. 36, pp. 21-23, 2015.

[2] Shangrao Vocational and Technical College, "Decision of the state council on accelerating the development of modern vocational education," http://www.srzy.cn/show.asp?id=512, 2016-9-29.

[3] C. X. Wang, "Status and role of teachers," http://www.zynews.com.cn/llyt/ShowArticle.asp?ArticleID=2649, 2016-9-30.

[4] C. M. Wang, "Research on the construction of the evaluation system of vocational education," Chinese Vocational and Technical Education, vol. 21, no. 15, pp. 41-43, 2013.

[5] X. Z. Tang, The Features of Market-oriented Vocational Education and Its Implication," Adult Education, vol. 34, no. 12, pp. 31-33, 2014.

[6] Q. L. Li, "Quality evaluation system of Vocational Education," http://www.xuexila.com/lunwen/edu/vocational/26200.html, 2016-9-27.

[7] F. W. Du, "Study on Training Countermeasure for Vocational Ability of Students in Secondary Vocational School Based on Evaluation of Employers," Master's degree of Hebei Normal University of Science \& Technology, 2014.

[8] N. Ding, "Research on Vocational Competence Cultivating Based on Synergy of Higher Vocational Education Students," Master's degree of Guangdong Polytechnic Normal University, 2014.

[9] J. Q. Shi, "The Enlightenment of the theory of multiple intelligences to the reform of secondary vocational education," Education Exploration, vol. 33, no. 3, pp. 19-20, 2013. 